\title{
Apresentação - Literatura: Em pauta: História da Literatura e Historiografia Literária
}

\author{
Maria Eunice Moreira ${ }^{1}$, Francisco Topa ${ }^{2}$
}

1 Professora da Faculdade de Letras da PUCRS. Tem Mestrado e Doutorado em Linguística e Letras (Teoria Literária) pela
PUCRS. Coordena o Curso de EspecialiPUCRS. Coordena o Curso de Especiall-
zação em Literatura Brasileira, da Faculdade de Letras da PUCRS. É editora das revistas Letras de Hoje e Navegações e membro do Centro de Literaturas de Expressão Prova de (CLEPUL), da Universidade Nova de Lisbo

Doutor; profucr.b.

de Letras da Universociado da Faculdade de Letras da Unversidade do Porto (Porde Investigaçẫo Transdisciplinar "Cultura, Espaço e Memória").

franctopa@gmail.com
A história da literatura tornou-se, nas últimas décadas, um campo de estudo renovador na área dos estudos literários. Ao desafio que provoca o discurso historiográfico é constante, e os modos de leitura e a interpretação de sua escrita permitem integrar diferentes produtos sociais e exigem do historiador uma postura consoante com o tempo e o lugar de onde fala. Isso porque a interpretação monolítica e linear sobre o passado literário cede lugar a um entendimento múltiplo e variado, que assume uma feição plural e transitória. História da literatura é, portanto, discurso que se escreve no plural e que se abre para múltiplas possibilidades de abordagens, focalizando acervos de escritores, textos produzidos ao longo dos séculos, possibilitando reavaliações de autores e obras, interrelações com outras áreas da cultura e abordagens teóricas inovadoras.

Desde a década de 1970, quando vigorava a visão imanentista do texto literário, até a atualidade, a história da literatura passou por uma reavaliação, privilegiando hoje a ótima mais interativa, em que o texto deixa de ser contemplação de um leitor para se tornar um produto que transcende o mero escrito, ou melhor, que vai além da página do livro, buscando sua historicidade e seu sentido na sociedade. Ler e analisar a história da literatura é, portanto, entrar nos meandros de um campo disciplinar do qual participam gostos pessoais, preferências teóricas sobre literatura e história, visões políticas, enfim, ramais e caminhos que falam do sujeito e de seu lugar social.

Ao propor um número da Letrônica - Revista Digital do Programa de Pós-Graduação em Letras da PUCRS sobre o tema da história da literatura, abrindo para um leque de leituras que se pretendia plural e múltiplo, os organizadores desse número foram plenamente atendidos. Os textos que compõem a presente Letrônica enfocam a rede complexa de interesses e estratégias que movimentam a história da literatura e que permitem conhecer, um pouco mais, as complexas relações 
que constituem o sistema literário, no qual manifestam-se múltiplos e intrincados fatores. Esse fato é positivo, pois é no espaço dessas relações cruzadas e intercambiáveis que o conhecimento se produz e se torna mais aberto à interpretação.

Os artigos reunidos nesse número podem ser agrupados em quatro conjuntos, a saber: 1 - no primeiro conjunto, artigos que tratam de questões historiográficas, do ponto de vista teórico ou das aproximações da história da literatura com outras áreas do conhecimento, como arquitetura e música; 2 - no segundo conjunto, reúnem-se os textos que abordam particularidades da vida literária, como é o caso do estudo sobre a fase francesa de Hemingway ou sobre a recepção do poeta português Luís António Vernei; 3 - o terceiro conjunto enfeixa ensaios que têm um ponto em comum: todos eles, com maior ou menos intensidade, valem-se dos periódicos literários para dali retirar a matéria para compor o ensaio. Três periódicos publicados no Rio Grande do Sul: o Koseritz Deutcher Volkskalender für Brasilien, a Revista do Globo e a Revista Província de São Pedro, em momentos distintos, foram importantes veículos do pensamento cultural gerado no Sul do Brasil, a que se junta a Semana Ilustrada, editado no Rio de Janeiro; 4 - o quarto e último conjunto enfoca especificamente obras de caráter historiográfico: Formação da literatura brasileira, de Antonio Candido, e experiências de história da literatura produzidas em Goa, que adentram à questão das literaturas coloniais e dos empreendimentos literários, em períodos de ocupação ou de diáspora, a que se acrescenta uma avaliação do Dicionário de autores dramáticos do Rio Grande do Sul, recentemente lançado.

O primeiro conjunto abre-se com o texto "A alteridade como fato e justificativa para a escrita de histórias da literatura", de Ana Maria Werheimer, em que a autora aborda o signo da alteridade como condutor da escrita do discurso historiográfico, a partir dos conceitos do historiador Michel de Certeau até aos de outro historiador e filósofo, Paul Ricoeur. Às postulações teóricas desses dois autores juntam-se também a abordagem sistêmica de Hans U. Gumbrecht e os elementos narrativistas da teoria de David Perkins, consoantes com as questões atuais sobre identidade e alteridade, presentes na escrita da história da literatura. Desse modo, a visão monolítica que consolidava a história da literatura abre-se para novas abordagens, trazendo à consideração a diferença, o outro, que também têm espaço na representação literária.

Outro ensaio investe na discussão teórica, valendo-se da poesia para delinear o percurso mítico e histórico desse gênero enquanto maldição. Desde Caim, o fratricida proscrito, como o identifica Gustavo Ramos de Souza, em "A literatura sob o signo de Caim: os gênios malditos", há uma relação entre o gênio criador e a melancolia/doença, o que permite discutir o texto literário e o teórico em equivalência de valor.

No estudo, "Historiografia literária e arquitetura: intercessões por uma escrita alternativa", Aline de Almeida Moura analisa experimentos contemporâneos de histórias da literatura norte-americana, alemã e francesa à luz de pressupostos teóricos provenientes da arquitetura pós-moderna, especialmente na relação que estabelece entre forma e função. Se o 
estudo colabora para a renovação do campo historiográfico, afirma também a aproximação entre essas duas áreas do conhecimento, que muito têm a dizer, reforçando a proposta interdisciplinar da historiografia literária contemporânea.

Das relações entre literatura e arquitetura, passamos à aproximação entre literatura e música, já bem mais conhecidas e palpáveis, sobretudo nos estudos literários brasileiros, em que música e literatura têm uma história antiga e fundamental. No século XIX, estudiosos da literatura brasileira apontavam para o caráter musical do texto poético e para a tendência musical dos poetas nacionais. Em “De poetas a músicos e de músicos a poetas: vanguardas em diálogos no Brasil”, Tiago Lopes Schiffner mostra a sintonia entre o movimento conhecido como Tropicalismo, do final dos anos 60 e início dos 70 , que invadiu a música brasileira, com o ideário do Concretismo, movimento poético das décadas anteriores, observando o compartilhamento de concepções artísticas e referências vanguardistas nas duas expressões artísticas.

O segundo conjunto, que inicia com o artigo de Francisco Topa, “E as fontes de longe miram: a lentidão da historiografia literária, a poesia de Vernei e o que falta fazer", incide sobre uma questão significativa da escrita historiográfica, qual seja o descompasso entre o tempo de investigação e o tempo da historiografia literária, tomando por referência a obra atribuída ao poeta Luís António Vernei, uma das mais representativas figuras do Iluminismo português, autor de $O$ verdadeiro método de estudar, de 1758.

Em compasso contrário, pois que com avaliação atual, Ernest Hemingway é presentificado no artigo de Luis Roberto Souza, intitulado "A história, e as histórias, em algumas cartas de Ernest Hemingway na Paris de 1920". O autor de $A$ vida é uma festa viveu o início de sua carreira na capital francesa, na década de 1920, momento em que a cidade atraía os prinicpias artistas do mundo e vivia o florescimento modernista. Tomando por referências as cartas de Hemingway, o ensaísta recupera as relações literárias e lugares de vivência do escritor.

O terceiro conjunto engloba quatro ensaios, cuja fonte de estudo é o periódico literário. Imgart Grützamnn analisa as representações da figura feminina em produções publicadas em um almanaque editado em língua alemã, no Rio Grande do Sul, no texto intitulado "Mulheres, casamento e maternidade: a recepção de autoras alemãs, austrícas e suíças no Koseritz Deutcher Volkskalender für Brasilien, contribuindo com sua pesquisa e análise para a história do livro e da leitura, na província sulina, através da colaboração estrangeira. O artigo de Diego Grando recai sobre a "Poesia na Revista do Globo: duas fases, duas faces", privilegiando esse gênero literário para levantar hipóteses sobre as mudanças estéticas e editoriais desse importante periódico porto-alegrense, ao longo sua história, em constraste com as visões proporcionadas pela historiografia literária. Fávio Varela Nascimento, em "Cyro Martins e a revista Província de São Pedro", toma por fonte a revista Província de São Pedro, também de Porto Alegre, para destacar a presença do escritor sul-rio-grandesne, Cyro Martins, nas páginas desse veículo, ora como crítico, ora como produtor literário. Nesse rastro de duas faces, busca 
elementos para reconstruir a trajetória de um indivíduo inserido no sistema cultural do Rio Grande. Em "Ridendo castigat mores: o combate às "pulgas parnásicas" nas páginas da Semana Ilustrada”, Adriana Dusilek vale-se da crítica literária, presente nesse periódico carioca, para identificar os traços poéticos dos "maus poetas" e, da análise desse parâmetros, em uma crítica às avessas, buscando definir os parâmetros estéticos que orientavam os críticos da Semana Ilustrada.

O último conjunto privilegia empreendimentos historiográficos de Goa, na Ásia, do Brasil e do Rio Grande do Sul, representados, respectivamente, pelas histórias da literatura produzidas na antiga colônia. Em "Historiografia literária e pós-colonialismo: o caso da literatura indo-portuguesa", Daniela Spina traça um panorama sobre a produção indoportuguesa, após 1961, ano que assinala o fim da ocupação portuguesa em Goa. São citados os estudos do Padre Filinto Cristo de Dias, a obra de Vimala Devi e Manuel de Seabra, respectivamente das décadas de 1960 e 1970, e livros mais atuais, como os do Padre Eufemiano de Jesus Miranda e outro de Joana dos Passos, autores que tratam da escrita da história da literatura da antiga colônia portuguesa na Ásia. A questão da literatura colonial volta à cena, em outra concepção, mas abordando também as relações entre literatura e a antiga metrópole, no texto de Yuly Paola Martínez, intitulado "Formação da literatura brasileira: o pensamento dialético de Antonio Candido". $\mathrm{O}$ artigo aborda a dialética presente na obra do mestre brasileiro, mostrando como esse pensamento fundamenta a construção de sua história da literatura. Por último, encerrando esse volume, Natasha Centenaro, em "Sobe o pano: Dicionário de autores dramáticos do Rio Grande do Sul, contribuição para a história da literatura”, analisa a profunda pesquisa desenvolvida por Antenor Fischer, que deu origem ao Dicionário de autores dramáticos. Relegado ao "segundo plano", nas histórias da literatura, o levantamento de Fischer inventaria o extenso elenco de autores e obras produzidas no Rio Grande do Sul, no século XIX, trazendo, segundo a autora do ensaio, elementos fundamentais para a construção de significado da sociedade que a representação teatral também pode produzir.

Espera-se, assim, que a variedade de estudos, presentes neste volume, aponte para a dinamicidade da história da literatura, na contemporaneidade, e ofereça ao leitor uma contribuição para conhecimento do estado atual da arte, nesse campo, estimulando fecundas hipóteses e renovadas investigações. 